\title{
PERCEPTUAL ANALYSIS OF L2 PHONIC COMPETENCE
}

The research is focused on the quality of English pronunciation of Slovak native speakers reflected in the score of perceptual evaluation by English native speakers. The primary objective is to detect the improvement of English phonic competence after the metaphonetic input focused on the contrastive analysis of the Slovak and English segmental systems.

Key words: L2 pronunciation - perceptual analysis - statistics

\section{Introduction}

From a percipient's point of view, the impression of "good" or "bad" foreign language (L2) pronunciation is dependent on many subsegmental, segmental, plurisegmental and suprasegmental phonic phenomena. Some studies [1] proved that many segmental sound substitutions significantly correlate with evaluating the pronunciation as non-idiomatic (non-native). However, the substitutions are not the only criterion. They are very easy to perceive, but the percipient's auditive impression represents a complex of phenomena and factors.

Besides the significant inter-individual variability of non-natives' phonic performance it is obvious that the majority of adult learners permanently speak L2 with a foreign accent without regard to the competence of other language levels. The ultimate level of a non-native speaker's pronunciation often reflects significant interindividual differences and intra-group tendencies. The primary objective of the research in this field should be the detection and verification of methods and techniques of L2 learning that help learners achieve high standards of L2 pronunciation effectively.

\section{Methodology}

The primary objective of our research was to detect the quality of the English phonic performance of adult Slovak speakers. The research was carried out before and after the speakers had received special metaphonetic input focused on the contrastive analysis of the English and Slovak segmental systems. The experimental and the control groups went through identical phonetic training focused on the segmental subsystem of the English language. The information the experimental group received during the training period was based on the comparative analysis of English and Slovak phonic systems [2]. On the other hand, the information provided to the control group included only the information about the English phonic (segmental) system without the Slovak-English contrastive aspects.

The first recordings of the respondents' spontaneous English monologues were made before the experiment was carried out (September). After 10 weeks of the theoretical input mentioned above and phonetic training in both groups more recordings were made (December). The audio-material was perceptually evaluated by four English native speakers (informants) who used a 5-point evaluation scale. The data obtained from the perceptual analysis were then evaluated through the basic descriptive statistical methods (mean, modus, median, standard deviation, variation coefficient).

We performed a longitudinal comparative quasi-experiment with two groups - the experimental group (E) and the control group (K). The intervention effect (metaphonetic input) was detected by the comparison of the pre-test $\left(\mathrm{E}^{1}-\mathrm{K}^{1}\right)$ and the post-test $\left(\mathrm{E}^{2}-\right.$ $\mathrm{K}^{2}$ ) data. We applied the covariation analysis in the experimental plan and we measured the dependent variables before and after the experimental intervention.

\section{Respondents}

We worked with the group of 80 Year 1 students (60 female, 20 male) who studied English Language and Literature at the Faculty of Science, University of Zilina, Slovakia. The average age of the respondents was 19, all of them were Slovak, their mother tongue was Slovak and they all reported normal hearing dispositions. Their average English lexical and grammatical competence was at the B1 and B2 levels (CEFR) ${ }^{1)}$. Most of them started learning English at the first level of elementary school with a non-native English teacher. Most of them have never stayed in an Englishspeaking country for a long period (months/years). We randomized the respondents into two quasi-homogeneous groups of 40 people (30 female, 10 male).

\footnotetext{
* Tomas Lengyelfalusy ${ }^{1}$, Zdena Kralova ${ }^{2}$

${ }^{1}$ Department of Mathematics, Faculty of Science, University of Zilina, Zilina, Slovakia, E-mail: tomas.lengyelfalusy@fpv.uniza.sk

${ }^{2}$ Department of English Language and Literature, Faculty of Science, University of Zilina, Slovakia

${ }^{1)}$ CEFR - Common European Framework of Reference for Languages.
} 


\section{Informants}

Four British native speakers (from the southern part of England: Brighton, London, Oxford $)^{2)}$ made the perceptual analysis of the respondents' English pronunciation. Concerning the gender structure of the group of respondents ${ }^{3)}$ we chose three female and one male informant to increase the compatibility of the experimental comparison.

The informants perceptually evaluated the respondents' pronunciation in a five-point interval scale ( 5 - very good pronunciation, 1 - poor pronunciation). The informants worked individually and were not informed about the evaluation of the other informants.

\section{Material}

The basic research material was the recording of the English monologues of each of the 80 respondents (the average length of 3.8 minutes). The recording was done in similar conditions, first in September (pre-test) and then, after ten weeks of specific metaphonetic input and phonetic training, in December (post-test). In order to maintain similar lexis and style of the respondents' utterances we chose an autobiographical topic. We considered the spontaneous monologue speech as more natural than reading isolated lexical units aloud. We tried to simulate a real language performance in which the speaker concentrates more on the contents than on the phonetic expression.

\section{Intervention}

In the experimental strategy we considered the equipment of relevant faculties in Slovakia. We did not want to apply the research in unrealistic laboratory conditions. The language departments frequently use available English textbooks with supplementary audiomaterials. The lectures for the experimental group were focused on the comparative analysis and practical presentation of the Slovak and English segmental systems with the emphasis on the potential phonic interference [2]. The lectures for the control group dealt with the English segmental system without mentioning the comparative aspect.

At the seminars both groups went through identical phonetic training focused on the segmental subsystem of the English language. The course followed the syllabus of the General and Comparative Phonetics and Phonology at the Department of English Language and Literature of the Faculty of Science, University of Zilina. Several techniques were applied during the course - the modification of the perceptual and articulatory base, the perception training, the articulation training in receptive and productive exercises combining imitative and analytical (cognitive) types of learning [3]

\section{Procedure}

\section{Pretest (September)}

1. We randomized 80 respondents into two groups - the experimental group and the control group, with respect to equal gender representation.

2. We recorded the spontaneous English monologues of each respondent using a condenser microphone.

3. The recordings were then evaluated by four English native speakers in a 5-point scale.

Intervention ( 10 weeks)

4. The respondents were provided the standard phonetic training in the seminars of the General and Comparative Phonetics and Phonology (50 minutes/once a week $)^{4)}$.

5. The contrastive (experimental group) and non-contrastive (control group) metaphonetic input was provided in the lectures of the course General and Comparative Phonetics and Phonology (50 minutes/once a week).

\section{Posttest (December)}

6. After 10 weeks of phonetic training we recorded spontaneous English monologues of each respondent in similar conditions as those in the pre-test.

7. The recordings were then evaluated by the same English native speakers in a 5-point scale.

8. We made the conclusions for the language system and the didactic practice.

\section{Discussion}

We calculated an average evaluation mark for each respondent and for the whole group based on the perceptual analysis of the native speakers in the pre-test and in the post-test. The data are statistically characterized by the parameters of position and variability (Table 1, Table 2).

Position parameters:

$\bar{x} \quad$ - arithmetic average of the data (mean);

$\tilde{x}$ - median (medium value, which divides the statistical set into two equal parts);

$\hat{x}$ - modus (the most frequent value of the statistical set).

Variability parameters:

$\sigma_{x}$ - standard deviation (absolute measure of variability);

$V_{x}$ - variation coefficient (relative measure of variability).

\footnotetext{
2) The British pronunciation standard, RP English, is taught at most of the Slovak universities in the given study programmes.

${ }^{3)}$ Male and female voices have different formant features which must be considered in the analysis.

4) We used a textbook with CD for the phonetic training [4], specifically Units 2-9 focused on the English segmental subsystem. We also used complementary material in both groups when needed $[5,6,7]$.
} 


\begin{tabular}{|c|c|c|c|c|c|c|c|c|c|c|c|}
\hline$E^{1}$ & 1 & 2 & 3 & 4 & $\bar{x}$ & $E^{2}$ & 1 & 2 & 3 & 4 & $\bar{x}$ \\
\hline 1 & 4 & 3 & 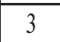 & 2 & 3 & 1 & 4 & 3 & I & 4 & 3.75 \\
\hline 2 & 2 & 1 & 2 & 2 & 1.75 & 2 & 3 & 3 & 4 & 3 & 3.25 \\
\hline 3 & 2 & 2 & 2 & 1 & 1.75 & 3 & 4 & 3 & 2 & 3 & 3 \\
\hline 4 & 2 & 2 & 3 & 2 & 2.25 & 4 & 4 & 3 & 3 & 3 & 3.25 \\
\hline 5 & 2 & 2 & 1 & 1 & 1.5 & 5 & 3 & 3 & 3 & 3 & 3 \\
\hline 6 & 3 & 3 & 3 & 4 & 3.25 & 6 & 4 & 3 & 3 & 4 & 3.5 \\
\hline 7 & 2 & 3 & 3 & 2 & 2.5 & 7 & 3 & 3 & 3 & 2 & 2.75 \\
\hline 8 & 3 & 2 & 3 & 3 & 2.75 & 8 & 3 & 3 & 3 & 3 & 3 \\
\hline 9 & 2 & 2 & 2 & 2 & 2 & 9 & 3 & 3 & 4 & 3 & 3.25 \\
\hline 10 & 1 & 2 & 1 & 2 & 1.5 & 10 & 3 & 2 & 2 & 2 & 2.25 \\
\hline 11 & 3 & 2 & 3 & 2 & 2.5 & 11 & 4 & 3 & 1 & 3 & 2.75 \\
\hline 12 & 2 & 2 & 2 & 1 & 1.75 & 12 & 2 & 3 & 3 & 2 & 2.5 \\
\hline 13 & 2 & 2 & 2 & 1 & 1.75 & 13 & 2 & 2 & 1 & 2 & 1.75 \\
\hline 14 & 3 & 2 & 3 & 3 & 2.75 & 14 & 4 & 4 & 4 & 3 & 3.75 \\
\hline 15 & 2 & 2 & 3 & 2 & 2.25 & 15 & 3 & 2 & 3 & 3 & 2.75 \\
\hline 16 & 3 & 3 & 3 & 2 & 2.75 & 16 & 3 & 3 & 3 & 3 & 3 \\
\hline 17 & 4 & 3 & 5 & 3 & 3.8 & 17 & 3 & 4 & 5 & 4 & 4 \\
\hline 18 & 4 & 3 & 4 & 2 & 3.25 & 18 & 4 & 3 & 3 & 3 & 3.25 \\
\hline 19 & 3 & 3 & 4 & 3 & 3.25 & 19 & 3 & 3 & 3 & 3 & 3 \\
\hline 20 & 5 & 4 & 5 & 4 & 4.5 & 20 & 5 & 5 & 5 & 5 & 5 \\
\hline 21 & 1 & 2 & 1 & 1 & 1.25 & 21 & 3 & 2 & 2 & 2 & 2.25 \\
\hline 22 & 4 & 3 & 4 & 3 & 3.5 & 22 & 3 & 3 & 3 & 3 & 3 \\
\hline 23 & 3 & 3 & 4 & 2 & 3 & 23 & 4 & 3 & 4 & 3 & 3.5 \\
\hline 24 & 3 & 2 & 3 & 2 & 2.5 & 24 & 4 & 2 & 3 & 3 & 3 \\
\hline 25 & 2 & 2 & 3 & 2 & 2.25 & 25 & 3 & 3 & 4 & 3 & 3.25 \\
\hline 26 & 2 & 2 & 3 & 2 & 2.25 & 26 & 2 & 3 & 3 & 3 & 2.75 \\
\hline 27 & 3 & 2 & 3 & 3 & 2.75 & 27 & 3 & 4 & 3 & 3 & 3.25 \\
\hline 28 & 3 & 2 & 2 & 3 & 2.5 & 28 & 3 & 4 & 4 & 3 & 3.5 \\
\hline 29 & 3 & 2 & 4 & 3 & 3 & 29 & 3 & 3 & 4 & 4 & 3.5 \\
\hline 30 & 2 & 2 & 3 & 2 & 2.25 & 30 & 3 & 2 & 3 & 3 & 2.75 \\
\hline 31 & 3 & 3 & 4 & 3 & 3.25 & 31 & 4 & 4 & 5 & 4 & 4.25 \\
\hline 32 & 3 & 2 & 4 & 3 & 3 & 32 & 4 & 3 & 3 & 4 & 3.5 \\
\hline 33 & 2 & 2 & 2 & 1 & 1.75 & 33 & 3 & 3 & 3 & 3 & 3 \\
\hline 34 & 4 & 3 & 4 & 3 & 3.5 & 34 & 4 & 4 & 4 & 4 & 4 \\
\hline 35 & 2 & 2 & 2 & 3 & 2.25 & 35 & 3 & 3 & 2 & 4 & 3 \\
\hline 36 & 3 & 2 & 2 & 1 & 2 & 36 & 3 & 2 & 3 & 3 & 2.75 \\
\hline 37 & 3 & 2 & 2 & 1 & 2 & 37 & 3 & 3 & 2 & 3 & 2.75 \\
\hline 38 & 1 & 2 & 1 & 1 & 1.25 & 38 & 2 & 2 & 1 & 2 & 1.75 \\
\hline 39 & 4 & 1 & 3 & 2 & 2.5 & 39 & 4 & 3 & 3 & 3 & 3.25 \\
\hline 40 & 3 & 1 & 3 & 2 & 2.25 & 40 & 4 & 3 & 3 & 3 & 3.25 \\
\hline $\bar{x}$ & 2.7 & 2.25 & 2.85 & 2.18 & 2.495 & $\bar{x}$ & 3.3 & 3 & 3.1 & 3.1 & 3.125 \\
\hline$x$ & 3 & 2 & 3 & 2 & 2.5 & $\tilde{x}$ & 3 & 3 & 3 & 3 & 3 \\
\hline$\hat{x}$ & 3 & 2 & 3 & 2 & 2.25 & $\hat{x}$ & 3 & 3 & 3 & 3 & 3 \\
\hline$\sigma_{x}$ & 0.91 & 0.63 & 1.03 & 0.84 & 0.72 & $\sigma_{x}$ & 0.69 & 0.68 & 0.98 & \begin{tabular}{|l|l|}
0.67 \\
\end{tabular} & 0.61 \\
\hline$V_{x}$ & 0.34 & 0.28 & 0.36 & 0.39 & 0.28 & $V_{x}$ & 0.21 & 0.23 & 0.32 & 0.22 & 0.20 \\
\hline
\end{tabular}

\begin{tabular}{|c|c|c|c|c|c|c|c|c|c|c|c|}
\hline $\mathrm{K}^{1}$ & 1 & 2 & 3 & 4 & $\bar{x}$ & $\mathrm{~K}^{2}$ & 1 & 2 & 3 & 4 & $\bar{x}$ \\
\hline 1 & 2 & 2 & 2 & 3 & 2.25 & 1 & 3 & 3 & 3 & 3 & 3 \\
\hline 2 & 2 & 2 & 2 & 2 & 2 & 2 & 3 & 2 & 1 & 2 & 2 \\
\hline 3 & 2 & 2 & 2 & 2 & 2 & 3 & 3 & 3 & 3 & 3 & 3 \\
\hline 4 & 1 & 2 & 1 & 2 & 1.5 & 4 & 3 & 2 & 1 & 3 & 2.25 \\
\hline 5 & 2 & 2 & 3 & 1 & 2 & 5 & 3 & 3 & 3 & 3 & 3 \\
\hline 6 & 3 & 2 & 3 & 1 & 2.25 & 6 & 2 & 3 & 2 & 3 & 2.5 \\
\hline 7 & 2 & 2 & 2 & 3 & 2.25 & 7 & 2 & 2 & 2 & 3 & 2.25 \\
\hline 8 & 2 & 2 & 2 & 2 & 2 & 8 & 3 & 2 & 3 & 2 & 2.5 \\
\hline 9 & 3 & 4 & 4 & 4 & 3.75 & 9 & 3 & 4 & 3 & 3 & 3.25 \\
\hline 10 & 4 & 3 & 3 & 3 & 3.25 & 10 & 4 & 3 & 3 & 3 & 3.25 \\
\hline 11 & 2 & 2 & 1 & 2 & 1.75 & 11 & 2 & 2 & 1 & 2 & 1.75 \\
\hline 12 & 3 & 3 & 2 & 3 & 2.75 & 12 & 4 & 4 & 4 & 4 & 4 \\
\hline 13 & 2 & 2 & 2 & 2 & 2 & 13 & 3 & 3 & 2 & 3 & 2.75 \\
\hline 14 & 3 & 5 & 5 & 4 & 4.25 & 14 & 4 & 5 & 5 & 5 & 4.75 \\
\hline 15 & 3 & 3 & 3 & 2 & 2.75 & 15 & 3 & 3 & 3 & 3 & 3 \\
\hline 16 & 3 & 2 & 3 & 3 & 2.75 & 16 & 4 & 4 & 3 & 3 & 3.5 \\
\hline 17 & 2 & 2 & 2 & 2 & 2 & 17 & 3 & 2 & 1 & 2 & 2 \\
\hline 18 & 4 & 3 & 3 & 3 & 3.25 & 18 & 4 & 4 & 4 & 4 & 4 \\
\hline 19 & 3 & 3 & 3 & 3 & 3 & 19 & 3 & 4 & 4 & 4 & 3.75 \\
\hline 20 & 2 & 2 & 3 & 2 & 2.25 & 20 & 2 & 3 & 2 & 3 & 2.5 \\
\hline 21 & 2 & 2 & 3 & 2 & 2.25 & 21 & 3 & 3 & 3 & 3 & 3 \\
\hline 22 & 2 & 2 & 2 & 3 & 2.25 & 22 & 3 & 2 & 2 & 3 & 2.5 \\
\hline 23 & 3 & 2 & 3 & 2 & 2.5 & 23 & 4 & 3 & 4 & 3 & 3.5 \\
\hline 24 & 3 & 2 & 3 & 2 & 2.5 & 24 & 3 & 3 & 3 & 3 & 3 \\
\hline 25 & 4 & 2 & 4 & 3 & 3.25 & 25 & 3 & 4 & 3 & 4 & 3.5 \\
\hline 26 & 4 & 2 & 4 & 2 & 3 & 26 & 4 & 3 & 4 & 4 & 3.75 \\
\hline 27 & 2 & 2 & 2 & 3 & 2.25 & 27 & 4 & 3 & 3 & 3 & 3.25 \\
\hline 28 & 3 & 2 & 2 & 2 & 2.25 & 28 & 3 & 3 & 2 & 3 & 2.75 \\
\hline 29 & 4 & 4 & 3 & 3 & 3.5 & 29 & 4 & 4 & 3 & 3 & 3.5 \\
\hline 30 & 1 & 1 & 1 & 2 & 1.25 & 30 & 3 & 3 & 3 & 3 & 3 \\
\hline 31 & 3 & 2 & 3 & 2 & 2.5 & 31 & 2 & 3 & 1 & 3 & 2.25 \\
\hline 32 & 2 & 2 & 2 & 3 & 2.25 & 32 & 3 & 3 & 3 & 4 & 3.25 \\
\hline 33 & 2 & 3 & 2 & 3 & 2.5 & 33 & 3 & 3 & 2 & 3 & 2.75 \\
\hline 34 & 3 & 3 & 2 & 2 & 2.5 & 34 & 3 & 3 & 2 & 2 & 2.5 \\
\hline 35 & 4 & 2 & 4 & 4 & 3.5 & 35 & 3 & 3 & 3 & 3 & 3 \\
\hline 36 & 1 & 2 & 2 & 2 & 1.25 & 36 & 1 & 1 & 1 & 2 & 1.25 \\
\hline 37 & 1 & 2 & 1 & 2 & 1.5 & 37 & 3 & 1 & 1 & 2 & 1.75 \\
\hline 38 & 3 & 3 & 4 & 2 & 3 & 38 & 4 & 3 & 3 & 2 & 3 \\
\hline 39 & 4 & 2 & 3 & 2 & 2.75 & 39 & 3 & 3 & 4 & 3 & 3.25 \\
\hline 40 & 2 & 3 & 3 & 3 & 2.75 & 40 & 3 & 3 & 3 & 2 & 2.75 \\
\hline$x$ & 2.575 & 2.38 & 2.6 & 2.45 & 2.488 & $\bar{x}$ & 3.07 & 2.95 & 2.64 & 3 & 2.913 \\
\hline$\tilde{x}$ & 2.5 & 2 & 3 & 2 & 2.375 & $\tilde{x}$ & 3 & 3 & 3 & 3 & 3 \\
\hline$\hat{x}$ & 2 & 2 & $2 ; 3$ & 2 & 2.25 & $\hat{x}$ & 3 & 3 & 3 & 3 & 3 \\
\hline$\sigma_{x}$ & 0.90 & 0.74 & 0.92 & 0.71 & 0.64 & $\sigma_{x}$ & 0.69 & \begin{tabular}{|l|}
0.82 \\
\end{tabular} & 1.02 & 0.69 & 0.48 \\
\hline$V_{x}$ & 0.35 & 0.31 & 0.35 & 0.29 & 0.26 & $V_{x}$ & 0.23 & 0.28 & 0.39 & 0.23 & 16 \\
\hline
\end{tabular}


Results of perceptual analysis

\begin{tabular}{|c|c|c|c|c|}
\hline & $\mathbf{E}$ & $\mathbf{K}$ & difference & $\%$ \\
\hline pre-test & 2.495 & 2.488 & 0.007 & 0.28 \\
\hline post-test & 3.125 & 2.913 & 0.212 & 6.78 \\
\hline difference & 0.630 & $\mathbf{0 . 4 2 5}$ & - & \\
\hline$\%$ & 25.25 & 17.08 & - & \\
\hline
\end{tabular}

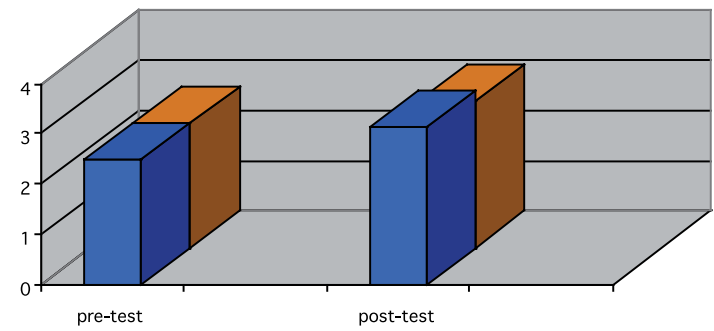

Fig. 1 Results of perceptual analysis

Limiting values of perceptual analysis

Tab. 4

\begin{tabular}{|c|c|c|c|c|}
\hline \multirow{2}{*}{} & \multicolumn{2}{|c|}{ pre-test } & \multicolumn{2}{c|}{ post-test } \\
\cline { 2 - 5 } & $\mathbf{E}^{\mathbf{1}}$ & $\mathbf{K}^{\mathbf{1}}$ & $\mathbf{E}^{\mathbf{2}}$ & $\mathbf{K}^{\mathbf{2}}$ \\
\hline $\min$ & 1.25 & 1.25 & 1.75 & 1.25 \\
\hline $\max$ & 4.50 & 4.25 & 5.00 & 4.75 \\
\hline
\end{tabular}

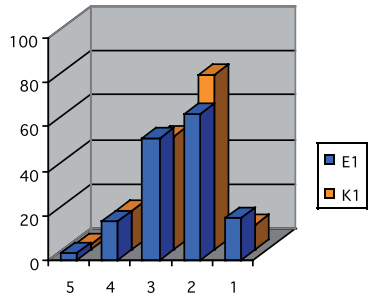

pre-test

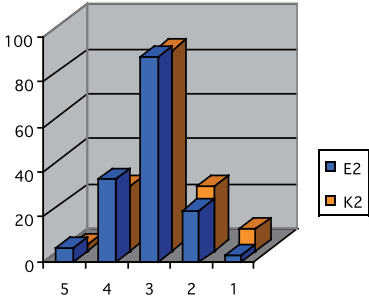

post-test
Fig. 2 Frequency distribution of the values

As can be seen in Table 3 and Figure 1 the average evaluation mark in the experimental group and in the control group was similar in the pre-test (difference $0.28 \%$ ). The average evaluation mark of the experimental group in the post-test was higher than the average evaluation mark of the control group (difference 6.78\%). While the improvement of the evaluation in the experimental group (pre-test vs. post-test) was $25.25 \%$, in the control group it was lower $(17.08 \%)$. The maximum and minimum pre-test values in both groups were similar (Table 4), but the limiting post-test values in the experimental group were higher than those in the control group.
The inter-individual variability of the evaluation shows relatively low variance of the values in a given phase of the experiment. An average pre-test and post-test variation coefficient in both groups was $V_{x}=22.5 \% .^{5)}$ The most frequent evaluation mark in the pretest was 2 and in the post-test it was 3 (Figure 2). Modus in both groups in the pre-test was 2.25 and in the post-test 3 .

\section{Conclusions}

We applied the synthesis of the theoretical analysis in the experiment and we detected the causal relations of the parameters by intentional manipulation of the independent variables and by the statistical analysis of the variables. We applied the covariance analysis in the experimental plan and we measured the dependent variable before and after the experimental intervention. The absolute randomization of the subjects was not possible in our experimental conditions so we applied the quasi-experimental method of the availability. We tried to interpret the results by the arguments resulting from the experiment which could approve or disprove the alternative theories.

The reliability of the measurement is approved by the agreement (measurement consistency) of the pre-test and post-test evaluation of an informant (test-retest reliability) with respect to the expected interaction of the maturation (the improvement of the respondents' pronunciation in a longitudinal design). The consistency of repeated measurements is approved by acceptable mean values $V_{x}$.

Besides the pre-test sensibilization (respondents' and informants') the interaction of maturation - the increase of experience - should be considered in the longitudinal type of experiment. In this case the interaction of maturation is one semester of the English language study which was partly eliminated by its homogeneous influence on all respondents.

The validity of measurements should be confirmed by the reliability of conclusions based on the measurements. To provide the internal validity we used statistical operations of the variance analysis. We tried to increase the external validity of measurements (possibility to generalize the results beyond an experiment) by work in fairly natural conditions - the common school environment and the research material reflecting natural communication.

One of the primary objectives of our research was to compare the effectiveness of the contrastive and non-contrastive metaphonetic input in teaching English phonetics and phonology at the university level in Slovakia. The abstract memory is intensively developing and the intentional type of memory is getting more effective with adult learners. The process of L2 pronunciation learning thus should be based on the theoretical information on the given activity. In case of adult learners the analytical (cognitive) type of phonetic training is considered to be more effective

\footnotetext{
${ }^{5)}$ Variation coefficient higher than 50\% indicates high heterogeneity of the statistical set [8].
} 
than the imitative type of training [3]. The awareness of differences, similarities and potential pronunciation mistakes (or deviations) resulting from the differences of the first and second language systems can contribute to the L2 phonic performance of an individual significantly.

Our research confirmed higher effectiveness of the contrastive metaphonetic input reflected in an overall quality of English pronunciation. Native speakers' perceptual analysis is subjective but the evaluation can be systematically interpreted and verified in an experiment. The level of an individual's phonic competence is often evaluated in terms of fluency and communicativeness of the speaker. However the interactive complexity of characteristics creating the final effect - L2 pronunciation - is undoubted. "Internal basis is an inseparable precondition of functionally adequate phonetic analysis of external speech factors" [9] and the performance is a point where the language - a potentially invariant and general phenomenon - meets with the variant and individual phenomenon - speech [10]

\section{References}

[1] FLEGE, J. E.: The Phonological Basis of Foreign Accent: A Hypothesis. In: TESOL Quarterly, vol. 15, 1981, n. 4, p. 443-455.

[2] KRALOVA, Z.: Slovak-English Phonic Interference [in Slovak]. Zilina: Faculty of Science, University of Zilina, 2005. 100 p. ISBN 80-89029-85-X.

[3] CHEBEnOVA, V.: Methods and Techniques in the German Pronunciation Training (I) [in Slovak]. In: Cizi jazyky, vol. 45, 20012002, n. 1, p. 6-8.

[4] ROACH, P.: English Phonetics and Phonology. Cambridge: Cambridge University Press, 1989. 280 p. ISBN 9521786134.

[5] O' CONNOR, J. D.: Better English Pronunciation. Cambridge: Cambridge University Press, 1980. 149 p. ISBN 0-521-23152-3.

[6] BAKER, A.: Ship or Sheep? Cambridge: Cambridge University Press, 1981. 168 p. ISBN 052128354-X.

[7] BOWLER, B., CUNNINGHAM, S.: Headway Pronunciation (Intermediate, Upper-Intermediate). Oxford: Oxford University Press, 1999. 63 p. ISBN 0-194-36245-0.

[8] HENDL, J.: An Overview of the Statistical Methods of Data Processing [in Czech]. Praha: Portal s. r. o., 2004. 584 p. ISBN 80-7178820-1.

[9] KRAL, A.: Speech Mechanism Model [in Slovak]. Bratislava: VEDA, 1974. 188 p.

[10] HLAVNOVA, A., HLAVNA, V.: Is language the final barrier in a shrinking world? In: Communications - Scientific Letters of the University of Zilina, vol. 5, 2003, n. 3, p. 96-97. 